\title{
Possibilidade de implementação de um programa de análise de perigo e pontos críticos de controle (APPCC) na preparação de salada de alface no restaurante universitário da Universidade Estadual de Londrina
}

\section{Hazard analysis and critical control points (HACCP) program implementation possibility during the preparation of lettuce salad served at State University of Londrina university restaurant}

\author{
Simone Palma Favaro ${ }^{1,2}$; Rosicler Balduino Nogueira ${ }^{1}$; Clarice Fujiko Yonemitsu ${ }^{3}$; \\ Massami Shimokomaki ${ }^{1}$
}

\begin{abstract}
Resumo: Foi desenvolvida uma avaliação sobre a possibilidade de implementar um programa de um sistema de Análise de Perigo e Pontos Críticos de Controle - APPCC, visando assegurar a inocuidade de hortaliças servidas como salada crua no Restaurante Universitário $(R U)$ da Universidade Estadual de Londrina, tomando-se como exemplo, a salada de alface. Avaliados os procedimentos das Boas Práticas de Fabricação, foi verificado que o RU apresentou boa parte dos requisitos necessários para que seja implantado o sistema APPCC. Foram listados os perigos químicos, físicos e biológicos para cada etapa da produção de salada de alface. Como pontos críticos de controle foram identificadas as etapas de recebimento (PCC químico), lavagem (PCC físico) e desinfecção (PCC biológico) e estabelecidas as medidas preventivas e de monitoramento.
\end{abstract}

Palavras-chave: Segurança alimentar, salada de alface, APPCC, restaurante universitário.

\begin{abstract}
The possibility of Hazard Analysis and Critical Control Points - HACCP- system implementation was evaluated at University Restaurant (UR) of State University of Londrina (UEL). A study was designed to assure the safety of vegetables served as raw salad. Lettuce salad was taken as example. After checking the Good Manufacturing Practice it was verified further that UR presented the necessary conditions to allow the HACCP system implementation for this product. The chemical, physical and biological hazards were checked throughout lettuce salad preparation and the critical control points were identified at raw material (CCP chemical), washing (physical CCP) and disinfecting step (biological CCP). Preventive and monitoring measures were also established in order to assure a safe lettuce salad provided by the UEL-UR.
\end{abstract}

Key words: Food safety, lettuce salad, HACCP, university restaurant.

\section{Introdução}

O consumo de alimentos visa atender os requerimentos nutricionais e sensoriais dos indivíduos, além da necessidade imprescindível de serem inócuos à saúde, ou seja, isentos de fatores biológicos, químicos e/ou físicos que possam trazer problemas à saúde do consumidor. Para assegurar a qualidade dos alimentos devem ser adotados diversos procedimentos em toda a cadeia envolvida na produção e comercialização destes produtos.

\section{Análise de Perigo e Pontos Críticos de Controle (APPCC)}

Uma das ferramentas mais eficientes no propósito de garantir a inocuidade é o sistema denominado Hazard Analysis and Critical Control Points (HACCP) que recebeu a denominação em português de Análise de Perigo e Pontos Críticos de Controle (APPCC) (CEZARI; NASCIMENTO, 1995). Este sistema consiste em estabelecer pontos de monitoramento, em uma linha específica de produção, de modo que se possam adotar medidas preventivas e, assim, garantir a segurança do produto final. A abordagem APPCC, não se baseia na forma tradicional de controle de qualidade de alimentos, onde a inspeção e os teste laboratoriais eram realizados no produto já acabado (APPCC, 1998).

Neste sistema se identificam os potenciais perigos associados a um alimento específico e rastreiam-se, em cada linha de produção, os pontos onde estes perigos possam eventualmente ser introduzidos ou alcançar níveis intoleráveis. Os perigos podem ser constituídos de agentes físicos (ex. partículas metálicas), químicos (ex. resíduos de agrotóxicos) e biológicos que englobam parasitas e microrganismos (HOBBS; ROBERTS, 1998). De acordo com o sistema APPCC, deve-se avaliar a

\footnotetext{
${ }^{1}$ Programa de Pós-graduação em Ciência dos Alimentos - Depto de Tecnologia de Alimentos e Medicamentos/CCA/UEL. Campus Universitário, Caixa Postal: 6001, CEP 86051-970, Londrina-PR.

2 Universidade Católica Dom Bosco - UCDB. Caixa Postal:100, CEP 79117-900, Campo Grande-MS.

${ }^{3}$ Restaurante Universitário - UEL. Campus Universitário, Caixa Postal: 6001, CEP 86051-970, Londrina-PR.
} 
gravidade destes perigos e os riscos de causarem doenças, determinar as situações nas quais estes perigos possam estar presentes e instituir medidas de controle, constituindo os pontos críticos de controle. Um ponto crítico de controle (PCC) é definido como um alimento cru, uma operação, uma fase ou uma etapa da cadeia do processamento do alimento, sobre o qual pode ser exercida uma medida preventiva ou de controle e onde a perda desse controle pode resultar em um risco inaceitável para a saúde do consumidor (ICMSF, 1991).

No Brasil foi instituída a obrigatoriedade da implantação do sistema APPCC em empresas de alimentação através da Portaria 1428 de 1993 do Ministério da Saúde, como mecanismo para garantir a segurança alimentar. No entanto, o número de estabelecimentos que tenham, de fato, implantado APPCC até o momento, é bastante reduzido. Alguns de seus planos têm sido divulgados através da literatura, como para estábulo leiteiro (SAKATE et al., 1999) e pratos a base de creme de maionese caseiro (RIBEIRO et al., 2000). Trabalhos como estes podem servir de base para elaboração de um programa de APPCC em linhas de produção semeIhantes.

Unidades produtoras de refeições coletivas, também estão incluídas na obrigatoriedade de apresentar programa de APPCC. No Brasil, a Associação Brasileira das Empresas de Refeições Coletivas (ABERC) estabelece critérios e normas para elaboração de refeições coletivas em Unidades de Alimentação e Nutrição (UANs). Estas normas incluem projeto e instalação da UAN, controle técnico de fornecedores, higiene dos manipuladores, higiene ambiental, higiene dos alimentos e noções básicas para implementação do APPCC (ABERC, 1998).

\section{Restaurante Universitário}

A Universidade Estadual de Londrina dispõe de uma UAN denominada Restaurante Universitário (RU), o qual está em funcionamento desde de abril de 1998 e atende à toda comunidade universitária, servindo atualmente cerca de 4000 refeições diárias, incluindo almoço e jantar. Embora não tenham sido registrados surtos de toxinfecção alimentar, existe a obrigatoriedade legal da elaboração e implantação do sistema APPCC. Para contribuir com a sistemática de garantia de qualidade, foi elaborado um programa de implementação de APPCC para a produção de hortaliças servidas cruas, tomandose como exemplo o alface.

\section{Objetivo}

Avaliar a possibilidade de implementar um controle de qualidade de vegetais consumidos crus através do programa de Análise de Perigo e Pontos Críticos de Controle (APPCC) na preparação da salada de alface no Restaurante Universitário da Universidade Estadual de Londrina.

\section{Desenvolvimento das etapas para elabo- ração e implantação do programa de APPCC}

O plano APPCC foi elaborado com base em visita in loco realizada no RU/UEL e na tomada de informações junto aos funcionários desta unidade. A seqüência das etapas foi discriminada com o auxílio do Guia para Elaboração do Plano APPCC (SENAI, 1998).

\subsection{Identificação completa da empresa}

Restaurante Universitário da Universidade, Universidade Estadual de Londrina, CNPJ 78640.489/0001/53.

\subsection{Elaboração do organograma}

O quadro funcional do RU está organizado de acordo com a Figura 1.

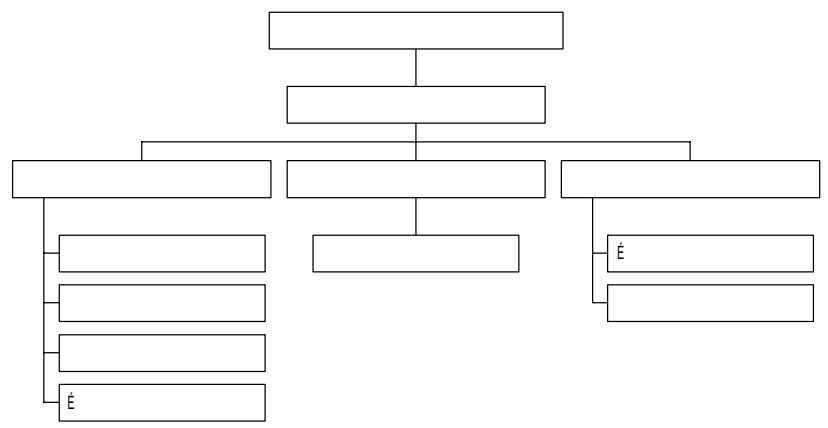

Figura 1 - Organograma do Restaurante Universitário da Universidade Estadual de Londrina.

\subsection{Definição da equipe}

Embora não tenha sido efetivamente constituída o time do APPCC, sabe-se que a equipe deve ser multidisciplinar e constituída por indivíduos envolvidos com as diferentes etapas do processo de produção, incluindo desde pessoal de cargo administrativo até auxiliares de cozinha. A equipe deve ter autonomia para tomada de decisões referentes à implantação do APPCC.

\subsection{Descrição do produto final}

O alface é distribuído na forma de salada crua sem adição de temperos em baixelas de cerâmica tipo aviação. Constitui-se num produto de relativa elevada atividade de água $(\mathrm{Aa}>0,97)$ e $\mathrm{pH}(\mathrm{pH}>4,5)$, com prazo de validade de 24 h quando mantido sob refrigeração $\left(10^{\circ} \mathrm{C}\right)$.

\subsection{Programa dos pré-requisitos}

Para implantação do APPCC, a UAN deve apresentar um conjunto de procedimentos e instalações físicas que estejam de acordo com normas estabelecidas pelas Boas Práticas de Fabricação (ABERC, 1998).

\subsection{Sanitização do ambiente}

A sanitização de superfícies de contato direto com alimentos e utensílios: lavagem com detergente, e 
enxágüe com água potável à temperatura ambiente e sanitização com cloro a 200 ppm ou álcool a 70 \% após o término de cada turno.

- Superfícies que não entram em contato direto com os alimentos: proceder limpeza e sanitização periódica para evitar o acúmulo de sujidades.

- Programa de controle integrado de pragas.

- Higiene periódica da caixa de água.

\subsection{Higiene do manipulador}

- Lavar as mãos constantemente com água e sabão próprio e fazer a assepsia com álcool 70 \% ou utilizar sabão anti-séptico.

- Não utilizar adornos e perfumes.

- Utilizar uniformes limpos e aventais sem bolso.

- Utilizar tocas e redes para cabelos.

- Controle de saúde (exames médicos periódicos).

\subsection{Processamento do produto}

- Seleção e descarte de material impróprio para o consumo e sujidades no ato do recebimento.

- Acondicionamento em caixas plásticas e armazenamento em câmara fria a $10^{\circ} \mathrm{C}$.

- Separação e seleção das folhas.

- Lavagem de folha a folha em água corrente potável.

- Imersão em solução clorada 150 a 200 ppm de cloro /15 min.

- Enxágüe em água potável.

- Fatiamento

- Porcionamento em monobloco higienizado de altura máxima de $10 \mathrm{~cm}$.

- Revestimento das bandejas com filme de PVC.

- Manutenção no "Pass Through" ou em câmara fria específica para produtos prontos para o consumo em temperatura inferior a $10^{\circ} \mathrm{C}$.

- Transferência para o balcão refrigerado $\left(8^{\circ} \mathrm{C}\right)$ para distribuição aos consumidores.

\subsection{Programa de capacitação técnica}

Para cumprir o programa de pré-requisitos, os manipuladores de alimentos devem ser treinados em BPF. A equipe formada para implantação do HACCP deve também ser treinada.

\section{Descrição do Fluxograma do Processo}

A produção de salada de alface se dá através das seguintes operações:

1) Recebimento: o alface é recebido em caixas de madeira.
2) Pré-limpeza: após o recebimento, o alface deve sofrer uma seleção prévia para retirada de folhas deterioradas e demais sujidades. A seguir deve ser transferido para recipientes plásticos higienizados.

3) Armazenamento: o alface que não for utilizado logo após o recebimento deve ser mantido em câmara refrigerada a $10^{\circ} \mathrm{C}$, específica para vegetais não higienizados, preferencialmente revestido com filme de PVC até sua utilização para evitar desidratação excessiva.

4) Seleção: as folhas devem ser destacadas eliminando aquelas que se encontram impróprias para o consumo por deterioração microbiana, danos físicos ou por desidratação excessiva. Devese eliminar também quaisquer sujidades.

5) Lavagem: as folhas selecionadas devem ser lavadas individualmente em água corrente potável, tomando-se o cuidado de retirar partículas de solo, fragmentos e ovos de insetos, pedras, lascas de madeira e outras sujidades.

6) Desinfecção: as folhas lavadas devem ser imersas em solução clorada com 150 a 200 ppm de cloro livre durante 15 minutos, assegurando que todo o conteúdo esteja imerso na solução. A fonte de cloro empregada deve ser aquela permitida para alimentos pela legislação em vigor.

7) Enxágüe: após a sanitização, as folhas devem ser enxaguadas em água potável para retirada do excesso de cloro.

8) Fatiamento: as folhas devem ser fatiadas sobre superfície impermeável previamente sanitizada e com o auxílio de instrumento de corte também sanitizado.

9) Porcionamento: após o fatiamento, o alface deve ser transferido para recipientes sanitizados (monoblocos) com altura máxima de $10 \mathrm{~cm}$ e revestidos com filme de PVC.

10) Espera: até a distribuição, o alface fatiado deve ser mantido em temperatura não superior a $10^{\circ} \mathrm{C}$, o que pode ser feito no "Pass Through" ou em câmara refrigerada específica para vegetais prontos para o consumo. O alface pode permanecer em temperatura superior a 10ํㅡ no máximo por 1 hora.

11) Distribuição: o alface porcionado deve ser colocado no balcão refrigerado até $10^{\circ} \mathrm{C}$ para ser transferido para o recipiente final a ser fornecido ao consumidor. Este recipiente deverá estar higienizado e ter dimensões suficientes de modo a permitir o acondicionamento adequado da porção fornecida.

A representação da planta baixa do RU (Figura 2) mostra a disposição das instalações e o fluxo que os vegetais servidos crus seguem desde o recebimento até sua distribuição. Como pode ser observado nesta ilustração, as operações com vegetais crus seguem um fluxo 
adequado segundo as normas de Boas Práticas de Fabricação, isto é, o risco de contaminação cruzada é baixo pois os vegetais já higienizados não entram em contato com aqueles ainda não higienizados e as instalações respeitam as condições estabelecidas de temperatura.

\section{Identificação dos perigos}

Os principais perigos de contaminação microbiológica em hortaliças, proveniente da matéria-prima, são Escherichia coli, Salmonella sp, Shigella, Bacillus cereus, Clostridium perfringens, Vibrio cholerae, bolores, leveduras, cistos de protozoários e ovos de helmintos. Em decorrência do contato com superfícies contaminadas como equipamentos e utensílios, manipulação ou o próprio ar, podem agregar-se Staphylococcus aureus, Pseudomonas aeruginosa além dos outros já citados (FRANCO, LANDGRAF, 1996). Os perigos químicos referem-se principalmente aos agrotóxicos utilizados durante o cultivo, ao cloro utilizado na higienização das folhas e aos resíduos de produtos de limpeza que podem ser agregados devido ao contato com utensílios e superfícies, cuja limpeza não foi realizada adequadamente. Os perigos físicos são principalmente àqueles decorrentes do sistema de cultivo ou material utilizado na embalagem e transporte como partículas de solo, pedras, pedaços de metal e arames e lascas de madeira. Os perigos para cada etapa do processo encontram-se listados no Quadro 1.

\section{Identificação dos Pontos Críticos de Controle (PCC s) através da Árvore Decisória}

O preparo da salada de alface foi analisado em suas diferentes etapas, desde o recebimento da matéria-prima até a distribuição ao consumidor. Para identificar os PCCs foi utilizada a árvore decisória apresentada pelo Guia para Elaboração do Plano APPCC (SENAI, 1998).

O recebimento foi identificado como PCC químico em função da possibilidade da presença de resíduos de agrotóxicos sistêmicos os quais não seriam eliminados em etapas posteriores. Portanto, este perigo deve ser eliminado nesta etapa através de uma seleção de fornecedores auditados.

A lavagem foi considerada como um PCC físico, pois cabe a esta etapa, a eliminação total das partículas macroscópicas responsáveis pelos perigos físicos.

A eliminação dos perigos biológicos provenientes da matéria prima é realizada durante a desinfecção constituindo-se, portanto, esta etapa num PCC biológico. Outros perigos biológicos podem ser agregados durante as manipulações seguintes, e entretanto, o cumprimento das Boas Práticas de Fabricação realizado com o devido cuidado pode eliminar estes perigos.

No Quadro 1 estão apresentados os PCCs com seus respectivos limites críticos, medidas preventivas e demais ações referentes ao Programa de APPCC.

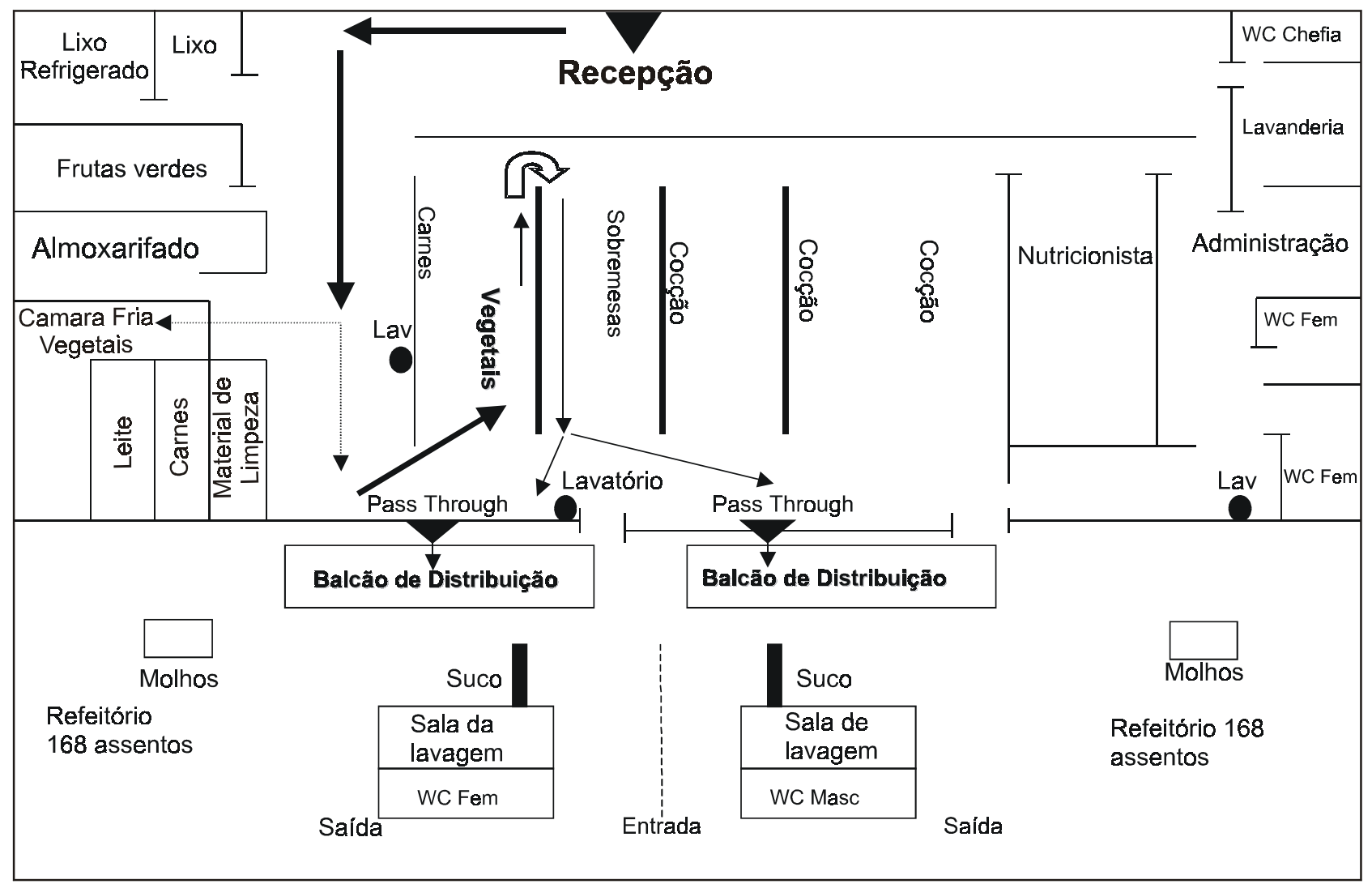

Figura 2 - Esquema da planta baixa do Restaurante Universitário da Universidade Estadual de Londrina (setas indicam o percurso seguido para o preparo e distribuição da salada de alface. 
Quadro 1 - Resumo do Plano APPCC para produção de salada de alface no Restaurante Universitário da Universidade Estadual de Londrina. 
Quadro 1 - Resumo do Plano APPCC para produção de salada de alface no Restaurante Universitário da Universidade Estadual de Londrina.

\section{Considerações Finais}

O RU/UEL apresenta boa parte do conjunto de prérequisitos necessários para implantação do programa de APPCC, sobretudo quanto aos aspectos de instalações físicas e nas operações de processamento das hortaliças. Há a necessidade de alterações no sistema de aquisição de matérias primas que atualmente se dá por licitação pública o que impede o estabelecimento de parceria com fornecedores. Além da necessidade de capacitação em APPCC de funcionários desta unidade. Esta proposta de programa de APPCC deve ser validada com as devidas correções para que este sistema possa ser implantado.

\section{Agradecimentos}

Ao Dr. Oswaldo Yokota, diretor do Restaurante Universitário da Universidade Estadual de Londrina e a todos os funcionários desta unidade. RBN e SPF são alunas do Programa de Pós Graduação em Ciência dos Alimentos do TAM/CCA-UEL. RBN é bolsista da CAPES e MS é pesquisador cientifico do CNPq.

\section{Referências}

ASSOCIAÇÃO BRASILEIRA DE EMPRESAS DE REFEIÇÕES COLETIVAS. Manual ABERC de Práticas de Elaboração e Serviço de Refeições para Coletividade. São Paulo, 1998
APPCC na Qualidade e Segurança Microbiológica de Alimentos: Análise de Perigos e Pontos Críticos - a Qualidade e Segurança Microbiológica de Alimentos. São Paulo: Varela, 1998

BRASIL. Portaria no. 1428 de 19 de Setembro de 1990. Regulamento Técnico de Inspeção Sanitária de Alimentos BPF/APPCC.

CEZARI, D. I.; NASCIMENTO, E. R.. Análise de Perigos e Pontos Críticos de Controle. Campinas: Sociedade Brasileira de Ciência e Tecnologia de Alimentos, 1995.

FRANCO, B.D.G.M.; LANDGRAF, M. Microbiologia de Alimentos. São Paulo: Ateneu, 1996.

HOBBS, B.T.; ROBERTS, T. Toxinfeccões e Controle Higiênico-Sanitário de Alimentos. São Paulo: Varela, 1998.

ICMSF. El sistema de analisis de riesgos y puntos criticos: su aplicacion a las industrias de alimentos. Zaragoza: Acribia, 1991.

RIBEIRO, L.L.; CARVALHO, E.P.; PILON, L. Análise de perigos e pontos críticos de controle no preparo de pratos à base de creme de maionese caseiro, em restaurante self-service. Higiene Alimentar, São Paulo, v.14, n.68/69, p.93-100, 2000.

SAKATE, R.I.; SANTOS, F. L.; CARDOSO, R.C.V.; BRANDÃO, S.C.C. Elaboração e Planejamento do Sistema HACCP para Estábulo Leiteiro. Higiene Alimentar, São Paulo, v.18, n. 65, p.30-36, 1999.

SENAI. Departamento Nacional Guia para Elaboração do Plano APPCC Série Qualidade e Segurança de Alimentos. Rio de Janeiro, 1998. 